\section{DUAL BAND LTE PLANAR INVERTED-F ANTENNA FOR M2M APPLICATIONS}

\author{
Abraham Loutrids ${ }^{1,2}$, Matthias John', Max J. \\ Ammann 1, 2 \\ ${ }^{1}$ Antenna \& High Frequency Research Centre, \\ Dublin Institute of Technology, Dublin 8, Ireland \\ ${ }^{2}$ The Telecommunications Research Centre (CTVR) \\ Trinity College Dublin, Dublin 2, Ireland \\ abraham.loutridis@mydit.ie
}

\begin{abstract}
A Planar Inverted-F Antenna for M2M applications is presented. The antenna is located on a rectangular ground plane and operates across both LTE frequency bands (690-960 MHz) and (1710-2690 MHz). The low cost antenna has omni-directional characteristics. The efficiency is better than $80 \%$ in both bands and the average gain is more than $-2.1 \mathrm{dBi}$ across the whole frequency range. A parametric study of key geometrical parameters is reported.
\end{abstract}

Key words: PIFA; LTE; M2M applications.

\section{Introduction}

Long Term Evolution (LTE) communication systems have been introduced recently, promising to provide greater capacity, throughput rates and better quality of service. For a variety of machine-to-machine (M2M) applications [1] many types of antennas have been reported, such as Planar Inverted-F Antenna (PIFA) antennas [2-5] and monopoles [6-8]. A broadband antenna is required to cover the whole frequency range of the lower and upper band of the LTE standard [8-10]. The performance of any broadband antenna is dependent on its geometrical characteristics and also the size and shape of the ground plane $[11,12]$ which is a criterion which strongly effects the broadband performance.

In this paper a PIFA structure which operates in the LTE bands $(690-960 \mathrm{MHz}) /(1710-2690 \mathrm{MHz})$ is presented for M2M applications. The proposed antenna provides a dual band operation with omnidirectional radiation characteristics, good impedance matching and high efficiency and gain. The effects of the geometrical characteristics of the antenna are studied.

\section{PIFA Antenna}

Figure 1 shows the geometry of the PIFA antenna, which is located on a ground plane of a single sided FR-4 substrate $\left(\varepsilon_{\mathrm{r}}=4.3\right.$, thickness $\left.=1.5 \mathrm{~mm}\right)$ with dimensions 178 $\mathrm{mm} \times 247 \mathrm{~mm}$ with metallization thickness $=0.035 \mathrm{~mm}$. The front and the back part of the PIFA antenna (Fig 1(a) and (b) $)$ are printed on FR-4 layers $\left(\varepsilon_{\mathrm{r}}=4.3\right.$, thickness $=1.5$ $\mathrm{mm}$ ) with dimensions $l=67 \mathrm{~mm} \times h=30 \mathrm{~mm}$. The top part of the PIFA antenna consists of a thin brass layer (thickness $=0.13 \mathrm{~mm}$ ) with dimensions $l=67 \mathrm{~mm} \times$ $w=33 \mathrm{~mm}$. The PIFA is fed via a $50 \Omega$ SMA connector through the ground plane to a feeding strip of $2.7 \mathrm{~mm}$ width which is located $a=20.5 \mathrm{~mm}$ from the left edge of the antenna.

The fold-over metallization lengths for the front and back sections are $d=23 \mathrm{~mm}$ and $b=12 \mathrm{~mm}$ respectively. The shorting strip is printed on a thin FR-4 layer (thickness $=0.2 \mathrm{~mm}$ ) and touches the inner part of the FR-4 back side layer (Fig. 1(d)). It connects to the top face of the antenna. The shorting strip width is $7.4 \mathrm{~mm}$ and is positioned $s=20 \mathrm{~mm}$ from the edge of the antenna. The antenna was modeled in CST Microwave Studio.

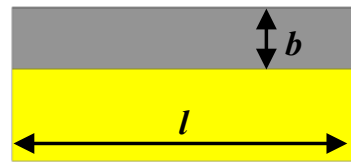

(a)

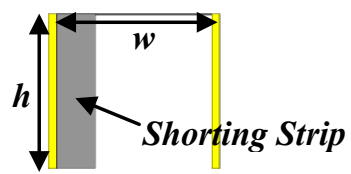

(c)

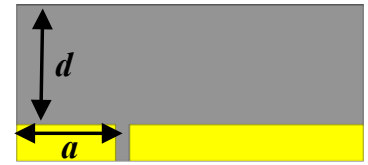

(b)

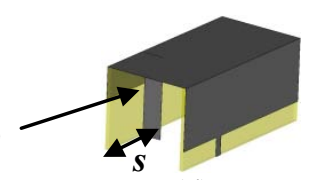

(d)
Figure 1 Rear view (a), Front view (b), Left view (c), General view.

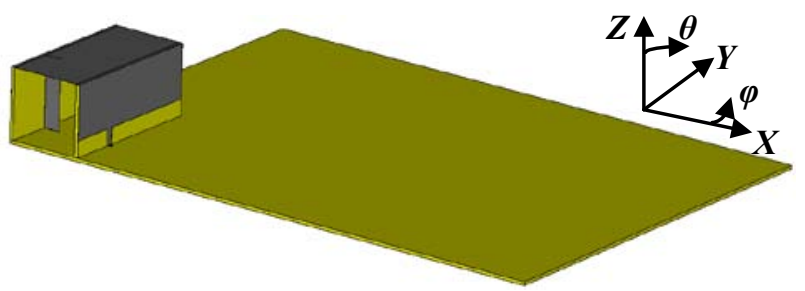

Figure 2 CST simulation model and the coordinate system.

\section{Parameter Study}

A parametric study of the four key parameters was made. Fig. 3 shows the simulated $\mathrm{S}_{11}$ as a function of the length $(l)$ of the PIFA antenna. From the graph it is seen that increasing the length of the PIFA antenna shifts the resonances downwards. The proposed value of the length $l$ for the proposed antenna is $67 \mathrm{~mm}$. 


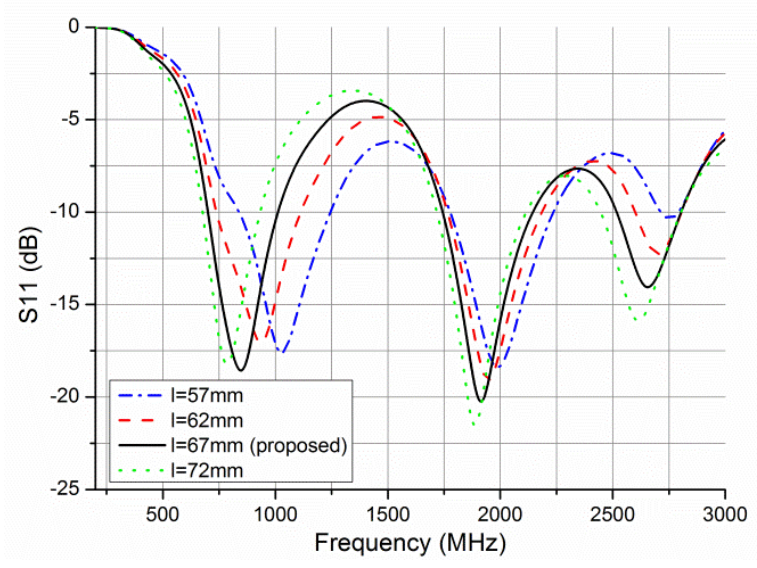

Figure 3 The simulated $S_{11}$ as the length $(l)$ of the PIFA is swept.

Fig. 4 shows the variation of the height $(h)$ of the PIFA antenna. As the height of the antenna increases, the impedance matching at the first resonance improves. On the other hand, for the second and third resonance as the height of the antenna increases the impedance matching deteriorates. The optimized value of the height $h$ for the proposed antenna is $30 \mathrm{~mm}$, providing good matching for both LTE bands.

In Fig. 5 simulated results for the width $(w)$ of the antenna are shown. As the value of width $(w)$ increases from $12 \mathrm{~mm}$ to $40 \mathrm{~mm}$, the low band degrades while the second band matching improves. A suitable value of the width $w$ of the antenna was chosen to be $33 \mathrm{~mm}$.

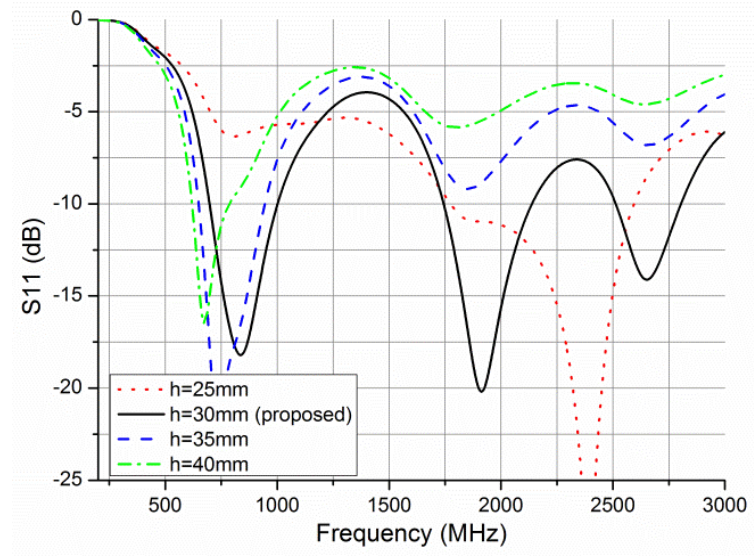

Figure 4 The simulated $\mathrm{S}_{11}$ as the height $(h)$ of the PIFA is swept.

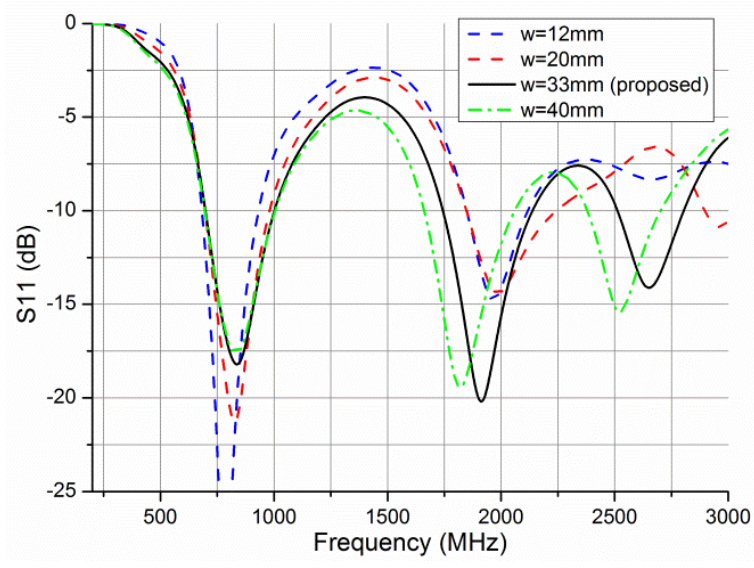

Figure 5 The simulated $\mathrm{S}_{11}$ as the width $(w)$ of the PIFA is swept.

Finally, in Fig. 6 the simulated $S_{11}$ results of the variation of the position $s$ of the shorting strip are shown. The obtained results clearly show that all resonant frequencies can be controlled (impedance matching and frequency shifting) by varying the parameter $s$. By considering the results of Fig. 6 the best value of the length $s$ is $20 \mathrm{~mm}$.

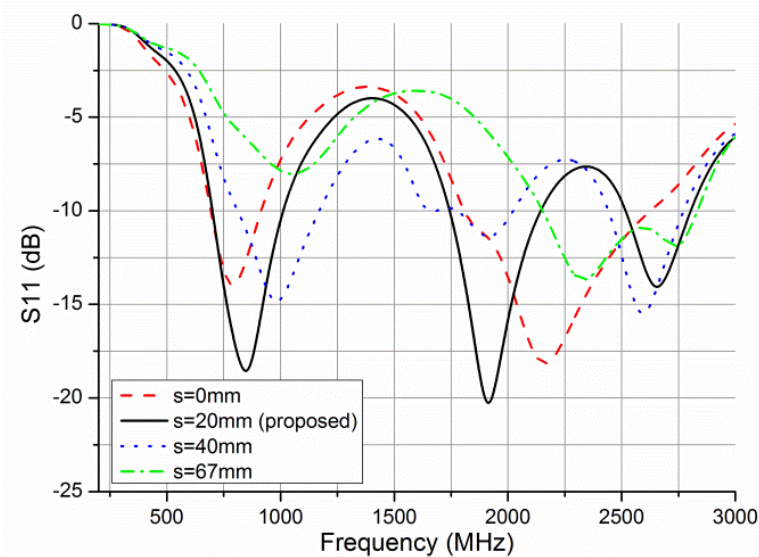

Figure 6 The simulated $\mathrm{S}_{11}$ showing the dependence on the shorting strip position $s$.

\section{Results}

The measured and simulated $\mathrm{S}_{11}$ are in good agreement as seen in Fig. 7. The $S_{11}$ was less than $-10 \mathrm{~dB}$ over the range $688.5 \mathrm{MHz}-1009.8 \mathrm{MHz}, 1736.3 \mathrm{MHz}-$ $2121.5 \mathrm{MHz}$ and $2459 \mathrm{MHz}-2698 \mathrm{MHz}$ giving fractional bandwidths of $40.6 \%, 20.87 \%$ and $9.31 \%$, respectively the frequency range for $\mathrm{S}_{11} \leq-6 \mathrm{~dB}$ is $623.5 \mathrm{MHz}-1111.8$ $\mathrm{MHz}$ and $1621.74 \mathrm{MHz}-3007.04 \mathrm{MHz},(62 \%$ and $75 \%$, respectively). 


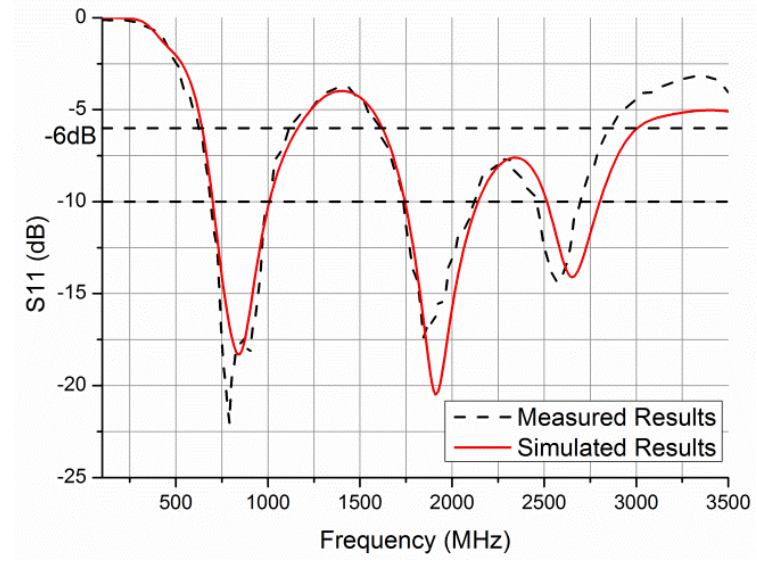

Figure $7 \quad S_{11}$ of the simulated and measured PIFA antenna.

In Figs. 8-13 the simulated and measured radiation patterns for $X Z, Y Z$ and $X Y$ planes at the LTE centre frequencies of $825 \mathrm{MHz}$ and $2200 \mathrm{MHz}$ are illustrated.

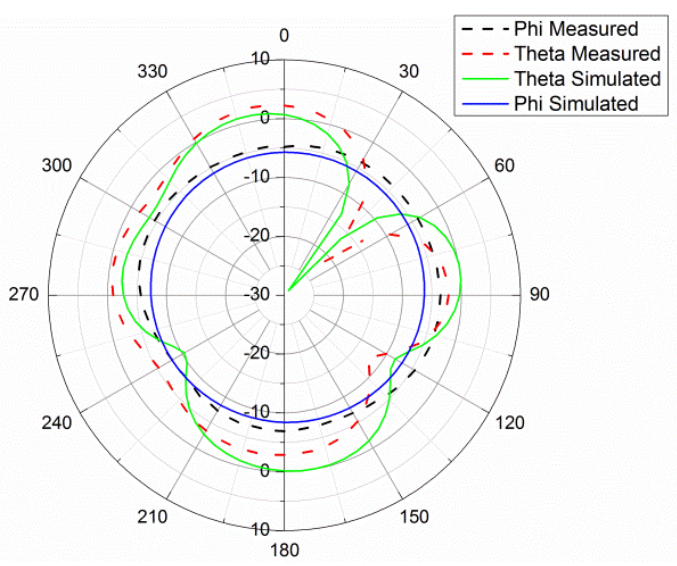

Figure 8 Measured and simulated $X Y$-plane patterns at $825 \mathrm{MHz}$.

At the three planes of $825 \mathrm{MHz}$ it is observed that the Phi $(\varphi)$ component provides good omnidirectional characteristics, which is also observed at the $X Y$-plane of $2200 \mathrm{MHz}$ for the Theta $(\theta)$ component. Moreover, at 825 $\mathrm{MHz}$ in the $Z Y$-plane good discrimination between the Phi $(\varphi)$ and Theta $(\theta)$ component is provided.

The measured maximum gain for the lower and upper band is $4.5 \mathrm{dBi}$ and $6.4 \mathrm{dBi}$, respectively. The measured gain, averaged over the principle plane cuts $(X Z, Y Z$ and $X Y)$ was $-1.1,-1.2$, and $-2.1 \mathrm{dBi}$ for the low band and -1.4 , -1.7 and $-1.6 \mathrm{dBi}$ for the high band. The simulated total efficiency is more than $82 \%$ and $80 \%$ for the first and for the second frequency band, respectively. The maximum total efficiency is $97.5 \%$ at $1915.4 \mathrm{MHz}$.

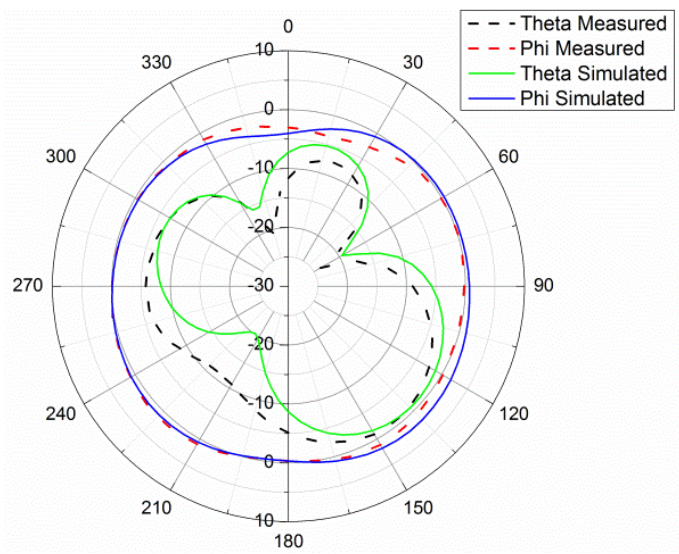

Figure 9 Measured and simulated $Y Z$-plane patterns at $825 \mathrm{MHz}$.

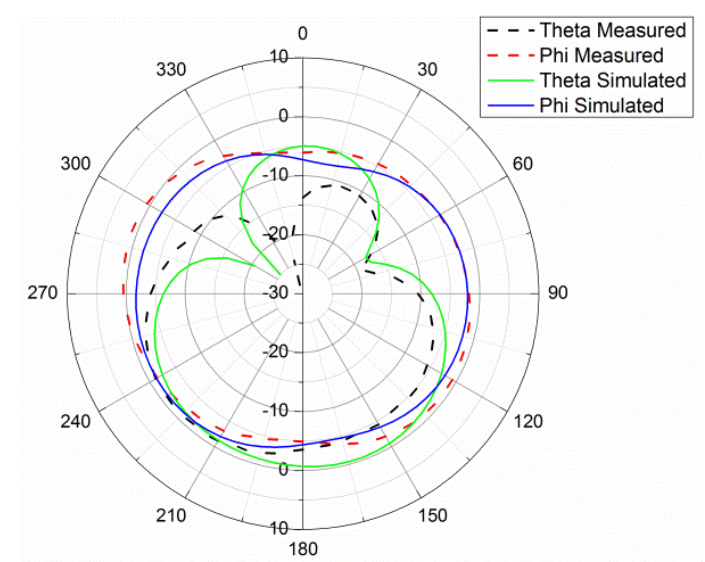

Figure 10 Measured and simulated $Z X$-plane patterns at $825 \mathrm{MHz}$.

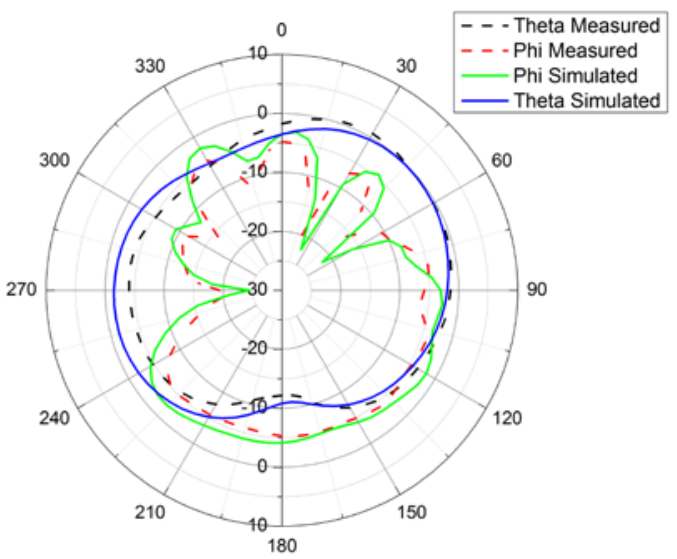

Figure 11 Measured and simulated $X Y$-plane patterns at $2200 \mathrm{MHz}$. 


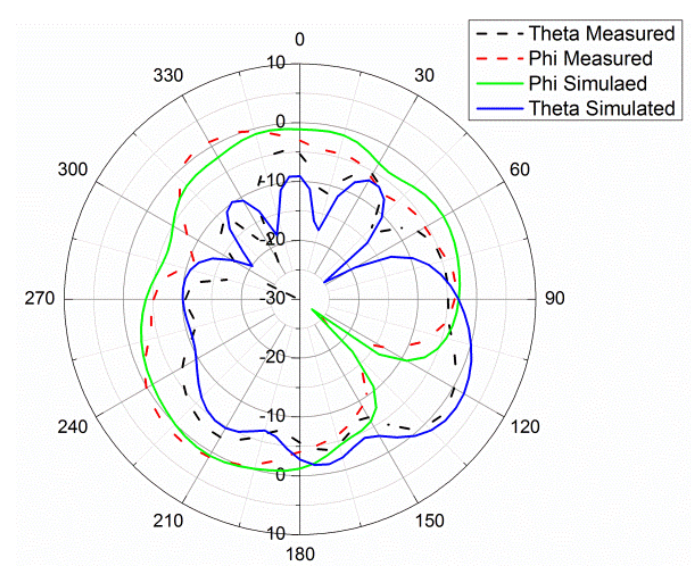

Figure 12 Measured and simulated $Z X$-plane patterns at $2200 \mathrm{MHz}$.

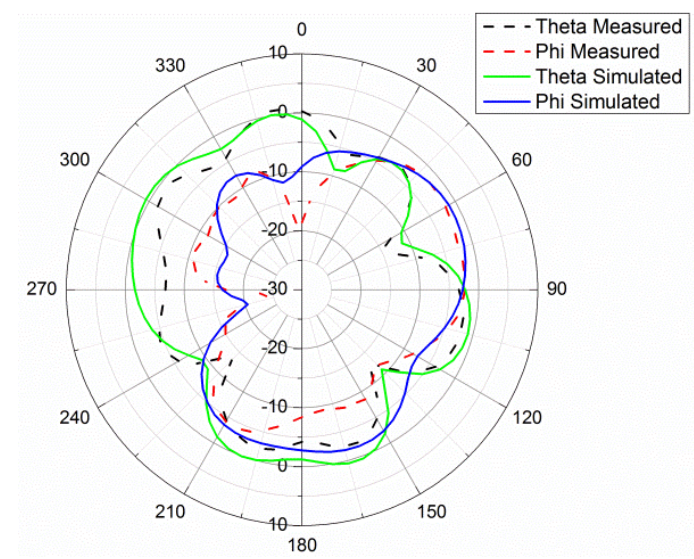

Figure 13 Measured and simulated $Y Z$-plane patterns at $2200 \mathrm{MHz}$.

\section{Conclusion}

In this paper a parameter study of a dual-band Planar Inverted-F Antenna (PIFA) for the LTE frequency range is presented. The proposed antenna which is suitable for M2M applications provides dual band operation, omnidirectional radiation characteristics, and high total efficiency in both bands and also good gain across the whole frequency range.

\section{Acknowledgements}

This material is based upon works supported by the Science Foundation Ireland under Grant No. 10/CE/I1853.
[3] D. Kearney, M. John, and M. J. Ammann, "Miniature Ceramic PIFA for UWB Band Group 3 \& 6", IEEE Antennas and Wireless Propagation Letters, vol. 9, pp. 28-31, 01/2010.

[4] Z. Li, Y. Rahmat-Samii, and T. Kaiponen, "Bandwidth study of a dual band PIFA on a fixed substrate for wireless communication," in Proc. IEEE Antennas Propag. Soc. Int. Symp., 2003, vol. 1, pp. 435-438.

[5] D. M. Nashaat and H. A. Elsadek, "Single feed compact quadband PIFA antenna for wireless communication applications,' IEEE Trans. Antennas Propag., vol. 53, no. 8, pp. 2631-2635, Aug. 2005.

[6] G. Ruvio, and M. J. Ammann, "From L-shaped Planar Monopoles to a Novel Folded Antenna with Wide Bandwidth", IEE Proceedings. Microwaves, Antennas \& Propagation, vol. 153, no. 5, pp. 456-460, 10/2006.

[7] G. Ruvio, and M. J. Ammann, "A Compact Wide-Band Shorted Folded Antenna", IEEE International Workshop on Antenna Technology: Small Antennas and Novel Metamaterials, White Plains, NY, USA, pp. 84-87, 06/03/2006.

[8] Wei-Yu Li, Chun-Yih Wu, Kin-Lu Wong and Ming-Fang Tu, "Internal Small-Size PIFA for LTE/GSM/UMTS Operation in the Mobile Phone", IEEE Antennas and Propagation Society International Symposium (APSURSI), pp. 1-4, 11-17 July 2010

[9] Kin-Lu Wong and Yu-Wei Chang, "Internal WWAN/LTE Handset Antenna integrated with USB Connector", vol. 54, Issue 5, pp. 1154-1159, May 2012

[10] Li-Jun Ying, Yong-Ling Ban and Jin-Hua Chen, "Low-Profile Coupled-Fed Printed PIFA for Internal Seven-Band LTE/GSMIUMTS Mobile Phone Antenna", IEEE Cross Strait Quad-Regional Radio Science and Wireless Technology Conference (CSQRWC), vol. 1, pp.418-421, 26-30 July 2011.

[11] M. John, and M. J. Ammann, "Optimum Design of the Printed Strip Monopole", IEEE Antennas \& Propagation Magazine, vol 47, no 6, pp. 59-61, 12/2005.

[12] M-C. Huynh, and W. Stutzman, "Ground plane effects on planar inverted-F antenna (PIFA) performance", IEE Proc. Microw. Antennas Propag. 2003, 150, (4), pp. 209-213.

\section{References}

[1] Cheng-Nan Hu, Willy Chen, J. -W Huang and Jack Chiu, "Design of a Multiband Coupled-Meander-Line Monopole Antenna for M2M Applications," International Conference on Applications of Electromagnetism and Student Innovation Competition Awards (AEM2C) IEEE, pp. 264-268, 11-13 Aug. 2010.

[2] K-L. Wong, "PLANAR ANTENNAS FOR WIRELESS COMMUNICATIONS”, Wiley, New Jersey, 2003. 